\title{
América do Sul: construção pela reinvenção (2000-2008)
}

South America: construction through reinvention (2000 - 2008)

THIAGO GEHRE GALVÃO*

Rev. Bras. Polít. Int. 52 (2): 63-80 [2009]

\section{Introdução}

Entre os anos 2000 e 2008, o edifício integrativo sul-americano passou por um processo de adensamento institucional e relacional. Todas as transformaçóes materiais tiveram respaldo na renovação do quadro de ideias que culminaram em uma nova fase da integração regional pela reinvenção do conceito de América do Sul. Nesse período, encontra-se a explicação do novo perfil de política exterior do Brasil que se apropria de elementos de alteridade como latino-americanidade, hegemonia, liderança e hispanidade para sua afirmação no plano internacional.

O objetivo específico deste artigo é lançar luz sobre o nexo entre ideias e política exterior atualizando as discussões sobre o conceito de América do Sul e a construção da política externa brasileira. O arcabouço teórico-metodológico parte do hibridismo História das Relaçooes Internacionais e Teoria das Relações Internacionais, especialmente o construtivismo social. Para tanto, o artigo está dividido em quatro seçóes principais: as origens intelectuais da ideia de América do Sul; a reinvenção da ideia de América do Sul; a sul-americanidade na construção de imagens; e a institucionalização da ideia de América do Sul.

\section{As origens intelectuais da ideia de América do Sul}

Há duzentos anos, o futuro da recém independente América Latina foi alvo de debate entre José Martí e Domingos Sarmiento. Ambos encarnavam duas correntes de pensamento que tentavam racionalizar um projeto de inserção da região nos moldes da cultura política e social do século XIX. Tal debate transfigurava-se na busca por uma identidade continental latino-americana, que poderia seguir por duas vias: a via da identidade ocidental da América Latina, amparada no progresso e civilidade provindos da Europa; e a via da autonomia latino-americana, que

\footnotetext{
* Professor do Departamento de Relações Internacionais da Universidade Federal de Roraima - UFRR (thiago.gehre@gmail.com).
} 
defendia a necessidade de se descobrir e enfatizar valores inerentes à América Latina. Além deles, Simon Bolívar inspirava-se nos ideais de liberdade e de democracia da Grécia Antiga e, ao convocar o Congresso Anfictiônico do Panamá, propunha a criação de uma confederação americana de estados preparada para agir defensiva e ofensivamente contra qualquer ameaça de dominação estrangeira, como a Santa Aliança (ALEIXO 2000, 170-191).

O debate propaga-se no tempo e alcança as chancelarias sul-americanas. No caso brasileiro, ele envolveu figuras importantes como Joaquim Nabuco, Oliveira Lima e José da Silva Paranhos, tendo como pano de fundo a mudança do eixo da política externa brasileira da Europa para os EUA e a aceitação da ideia de (pan) americanismo como horizonte da inserção internacional na fase de transição do Império para a Primeira República. O Barão do Rio Branco, à frente da pasta das relações exteriores, procurou equilíbrio em dois eixos de atuação: uma aliança tácita com o parceiro hegemônico da região, os Estados Unidos da América, para em seguida buscar a conformação de um espaço de paz e relações privilegiadas com seus parceiros sul-americanos. De fato, com Rio Branco, o continente sulamericano tem sua importância colocada sobre novas bases na diplomacia brasileira (BUENO, 2003; RICUPERO, 1995).

Em breve, o século XX veria eclodir as origens intelectuais da ideia de América do Sul refletida em duas imagens de alteridade: um ideológico central, definido pela americanidade e pela vinculação aos Estados Unidos; e um ideológico periférico, definido pela latino-americanidade e vinculado ao passado colonial. O debate ganha duas direçôes: a primeira, indicava a necessária e quase inevitável aproximação com o pólo central de poder político e econômico como caminho para o desenvolvimento. A segunda, que a América Latina respondia a desafios semelhantes e seria vínculo suficientemente forte para aglutinar os países em um mesmo plano da realidade. Como aponta Cervo, historiadores e teóricos do norte refletem os interesses de seus países em seus estudos, teorizações e conceituações, espelhando visões e alimentando objetivos das respectivas políticas exteriores (CERVO 2008, 13).

América Latina como abstração geográfica desenvolveu-se e ganhou força com o passar do tempo, chegando a caracterizar linhas de estudos nas principais universidades estadunidenses e vertentes de política externa direcionadas para uma região como se esta fosse um só país. Entretanto, as similitudes no que concerne a um passado histórico colonial e a necessidade de superação do subdesenvolvimento simplificam demasiadamente a complexidade dos países que compartilham, dentro de uma área de dimensões vastas, elementos culturais próprios e, conseqüentemente, interesses nacionais distintos.

De fato, a evolução latino-americana, como uma região historicamente fragmentada no quadro da divisão internacional do trabalho, o processo de industrialização tardio, bem como a forma particular de dependência que se estabeleceu entre os países da região e os Estados Unidos catalisaram a construção 
mental de uma realidade histórica: a diferenciação entre duas Américas, uma anglo-saxã integrada à economia mundial; e outra latina, com origens ibéricas relegadas à periferia deste sistema. (FURTADO 1970, 20; SINGER, 1997). Portanto, a configuração do "sistema mundo" - pensado como uma divisão entre centro e periferia - e a ideologização da relação de poder e dependência entre estas duas grandes regiōes fizeram com que tal ideia de América Latina viesse a perdurar no debate desenvolvimentista das décadas de 1960 e 1970.

Nos anos 80 e 90, o processo de formação do Mercado Comum do Sul evidenciou um corte específico da realidade para decisores e intelectuais. O Cone Sul trouxe efervescência para a produção em Relações Internacionais, desde os aportes político e histórico, até as vertentes teóricas e do processo negociador. Por um lado, tal fenômeno foi positivo uma vez que trouxe luz a uma realidade até então pouco estudada - a da integração e cooperação internacional do Brasil - ao mesmo tempo em que abriu novos questionamentos acerca do futuro do regionalismo no mundo. Por outro, foi negativo, ao restringir os estudos às relações dos dois principais parceiros do Mercosul, Brasil e Argentina.

Se considerarmos a criatividade como o principal meio pelo qual os intelectuais colaboram com a transformação das sociedades, os modelos de representação da realidade são símbolos das peculiaridades culturais de uma civilização ou sociedade (FURTADO 2002). Portanto, as origens intelectuais da ideia de América do Sul ganham forma quando a realidade da vida internacional faz da região um sistema integrado em termos de relações sociais, políticas, econômicas, estratégicas e culturais, emanadas não só do Cone Sul, como também das regiōes andina, amazônica, do pacífico e do atlântico.

Ao falar sobre a história do Cone Sul, Heredia $(1998,124)$ aponta que este não pode ser entendido, nem plenamente explicado, fora do contexto mais amplo de América Latina. Igualmente, o conceito de América do Sul, como uma categoria atualizada das Relações Internacionais, se vincula à consolidação da entidade geográfica com uma dinâmica própria na sociedade internacional. Com isso, a América do Sul acopla-se aos debates sobre regionalização e globalização. Por um lado, a contiguidade geográfica é elemento determinante para impulsionar a cooperação internacional na área de infraestrutura de integração e em contraposição ao ideológico latino-americano emerge a noção de um espaço sul-americano integrado. As fronteiras são repensadas e deixam de constituir elemento de separação e isolamento, e tornam-se importante elo entre os vizinhos. Conforme Albuquerque (1997): "A América do Sul é, antes de mais nada, um acidente geográfico [e por isso] mais palpável que a [noção de] América Latina, uma invenção que espelhou mais a percepção dos intelectuais europeus do que uma unidade real”.

Por outro lado, a América do Sul seria a "única forma de assegurar aos países da região a preservação de sua autonomia nacional, nesta gigantesca e desnacionalizadora onda de globalização" (JAGUARIBE 2000). O concreto geográfico valoriza diversidade e especificidade de cada sub-região americana, sendo "las diferencias 
culturales que hacen más factíbile soportar la homogeneidad del mundo globalizado". (Rapoport 2002, 128). Destarte, a América do Sul adquire traços próprios e características que a distingue do restante da região denominada América Latina. Com isso, a noção de América do Sul ganhou força como nível de análise para entender a inserção de seus países num "sistema mundo" em crescente globalização. Seria, enfim, inspiradora na formulação de agendas e no desenho de políticas públicas. Como atesta Seixas Correa (2000): "Em uma série de temas, a adoção de um enfoque específico sul-americano mais estruturado aportará um enriquecimento ao processo mais amplo de integração latino-americana e caribenha”.

Em síntese, América Latina e América do Sul são imagens diferenciadoras criadas e projetadas na interação entre o interno e o internacional. Entretanto, a ideia de América do Sul é referencial intelectual nem sempre entendido como nascente de um processo de co-constituição, mas do abandono de uma tradição por outra. Não obstante, as duas imagens tornam-se dimensões simultâneas de atuação internacional e, nesse sentido, a vizinhança brasileira passa por um processo histórico de adensamento pela identificação de mais uma camada de atuação internacional.

\section{A reinvenção da ideia de América do Sul}

Várias são as vozes na academia e na diplomacia brasileira que acreditam na política externa do governo Lula como herdeira da tradição diplomática de Rio Branco. Para tanto, exercitam nos discursos, pelos atos da fala e no jogo da linguagem, a construção de ideias e conceitos que resgatam tradiçôes estabelecidas nas práticas diplomáticas nacionais. Como lembra Onuf $(1998,64)$, "a repetição constante de discursos e sua aceitação como significante o torna uma convenção que relembrará os agentes, o que eles têm sempre feito".

Entretanto, percebe-se que alguns desses conceitos e ideias estão ancorados em tradições inventadas. Segundo Hobsbawn (2002, 9-22), "tradição inventada" diz respeito a práticas de natureza ritual ou simbólica que visam inculcar certos valores e normas de comportamento mediante a repetição, o que implicaria uma automática correlação legitimadora com o passado. Desta forma, a reinvenção da ideia de América do Sul remete ao contexto atual da discussão, à inserção do conceito na diplomacia brasileira, à função da América do Sul como identificador regional e à construção da identidade sul-americana.

\section{Contexto atual do debate}

Por que discutir a reinvenção da ideia de América do Sul? Partindo-se do pressuposto de que tal reinvenção é fruto da criatividade intelectual e da expertise diplomática, três tendências suportam as discussōes empreendidas neste artigo: as modificações da realidade internacional e do contexto regional sul-americano, a 
unicidade do pensamento em torno da ideia de América do Sul e as imprecisões conceituais e teóricas sobre a ideia de América do Sul.

No início do século XXI, a América do Sul passou por transformações significativas em seu perfil identitário. A deterioração dos modelos de desenvolvimento econômico fez recrudescer regimes de esquerda com projetos de cunho alternativo, ao mesmo tempo em que refluxos nacionalistas enfraqueceram o quadro democrático da região. Concomitantemente, a nova onda bolivariana, de conformação de sociedades mais justas com base nos ideais de Simon Bolívar, espalhou-se da Venezuela e contaminou Bolívia e Equador, criando pólos de oposição no sistema sul-americano. Com isso, tensões e atritos colocaram em choque Brasil e Venezuela, no caso do Mercosul; Argentina e Uruguai no caso das papeleiras; Brasil e Paraguai no caso de Itaipu; Colômbia, Equador e Venezuela no caso das FARCs; Brasil e Bolívia no caso do gás; e novamente o Brasil, desta vez com o Equador no caso da Odebrecht, que resultou na convocação do embaixador brasileiro em Quito para consulta. Como conseqüência, o conceito de América do Sul como ponto focal da política externa brasileira teve sua validade desafiada pelas contingências históricas.

Em segundo lugar, vale questionar a unicidade do pensamento que atribui à sul-americanidade brasileira um caráter determinista. Assim, trata-se de criticamente recolher os vestígios do ocaso da ideia de América do Sul que parecem rondar os corredores do Itamaraty ao se tomar consciência da multiplicidade constitutiva da identidade internacional brasileira e ao se admitir que a vocação do país parece mais fortemente atrelada ao universalismo. Para alguns, "são ações concretas que tornam o conceito de América do Sul nítido e inequívoco" (COUTO 2007, 163), o que é coerente com o processo de institucionalização de ideias. No entanto, o que precisa ser evidenciado é que ideias são criadas, inventadas, forjadas e acopladas ao discurso diplomático para daí seguir o caminho da institucionalização.

Por último, a atualidade da discussão se refere à tentativa de precisar conceitualmente a ideia de América do Sul pela composição histórico-teórica. Assim, a invenção da tradição de sul-americanidade atrelada à política externa brasileira não significa a propagação de uma inverdade, mas a reconstrução do mundo a nossa volta, ou seja, um espaço sul-americano organizado que visa restabelecer o prestígio internacional de seus Estados e os afastar do estereótipo latino-americano atrasado e subdesenvolvido.

\section{A inserção do conceito na diplomacia brasileira}

O processo de invenção da ideia de América do Sul passa por três momentos: apropriação e retorno às origens intelectuais, inserção da ideia no discurso diplomático e utilização como conceito para explicar a atualidade da política internacional em seus diferentes meios sociais. Ao mesmo tempo, o processo de invenção sofre influência do mundo acadêmico e intelectual que vai tanto 
respaldar quanto criticar a sua utilização, colaborando, das duas maneiras, para sua perpetuação como uma tradição.

As origens intelectuais, descritas anteriormente, possuem vínculo estreito com a prática diplomática brasileira do final do Império e início da República. A política externa brasileira à época do Barão do Rio Branco sinalizou o uso da ideia de América do Sul e valorizou a força da tradição como meio de inserção internacional. Para Rio Branco, tradição se referia a padrões históricos autoconstituídos que serviam como mapas para a tomada de decisão, o que não significava que sempre deveria agir de acordo com a "tradição". Por exemplo, quando contraria a tradição que reconhecia o Acre como território boliviano, Rio Branco considerou-o litigioso em favor do pragmatismo dos interesses nacionais frente à penetração imperialista norte-americana no caso do Bolivian Sindycate. Ao contrário, ao apoiar a Doutrina Monroe e idealizar o Pacto ABC, envolvendo Argentina, Brasil e Chile, Rio Branco definia a América do Sul como esfera de influência do Brasil, aceitando a América do Norte e o Caribe como esferas de influência dos Estados Unidos. Com isso, inventa a tradição da atuação em condomínios de poder, que de certa forma persiste até hoje (BANDEIRA 2003, 77).

Segundo Danese (1999, 29-33), a inserção no discurso diplomático brasileiro de um conceito o torna núcleo organizador da ação diplomática, estratégia de atuação e catalisador do comportamento externo de todo o governo. Assim, entre outubro de 1992 e maio de 1993, Fernando Henrique Cardoso (FHC), ainda como Ministro das Relações Exteriores, inicia a substituição da ênfase de América Latina para América do Sul, delimitando uma nova esfera geográfica prioritária da política externa brasileira. Recorda Luiz Felipe Lampreia (2000a) que a diplomacia brasileira já começara a preparar a mudança há algum tempo "desde que Fernando Henrique Cardoso foi chanceler, no início dos anos 90, transformar a América do Sul num conceito cada vez mais operacional para o conjunto das nações do continente". Dessa maneira, a diplomacia presidencial exercitada por FHC ao longo da década de 1990 foi profícua em difundir a ideia de América do Sul como parte integrante da identidade internacional do Brasil.

A ideia de América do Sul passa a ser elemento constitutivo da realidade na medida em que orienta o incremento do processo de integração pela infraestruturação da região. Por exemplo, na confecção de uma malha viária ligando o Brasil a seus vizinhos, na abertura de passagens para a integração transfronteiriça, ao conectar a Zona Franca de Manaus com o norte da América do Sul e ao projetar um caminho entre o Pacífico, a Amazônia e o Caribe. Assim, a importância de avançar questôes de infra-estrutura responsáveis por valorizar os contatos fronteiriços entre os vizinhos mediterrâneos e setentrionais é uma evidência empírica de que a ideia de América do Sul estabelece regras de convivência entre seus países.

$\mathrm{Na}$ medida em que a ideia reverbera nos discursos do Ministro de Estado e do Secretário-Geral do Itamaraty e encontra abrigo na intelectualidade nacional e sul-americana, se cristaliza em um conceito. Langehoven e Slocum (2005, 138 e 
142) afirmam que é empregando conceitos que nós damos sentido a eles e como todos os conceitos "they are created and reproduced by persons in discourses", o que inclui a criação de um senso de homogeneidade e um sentimento de singularidade identitária. Da mesma maneira, Adler (2002) aponta que a linguagem funciona como mecanismo de construção da realidade sendo veículo de difusão e institucionalização de ideias e gerando condições de persistência. Sinteticamente, para Onuf, "falar é sem dúvida a forma mais importante de fazer o mundo como ele é" (ONUF 1998, 59).

Assim, a sistemática utilização do conceito de América do Sul nos discursos oficiais e as modificaçôes estruturais iniciadas no ano 2000 na gestão Cardoso, e continuadas pelo governo Lula, no sentido da integração e aprofundamento do quadro institucional regional, revalidam a tradição da ideia de América do Sul, não apenas para a política exterior do Brasil, como também para seus vizinhos. Da mesma forma, a complexidade do mosaico regional torna-se inteligível à luz da sul-americanidade nas noções de identidade e identificação, pelo discurso diplomático e como conceito paradigmático de política exterior.

\section{América do Sul como um identificador regional}

A noção de identificação regional está atrelada a um conjunto de elementos que seguem critérios etnográficos, geofísicos e geopolíticos, na caracterização de fronteiras definidoras de lugares na paisagem sul-americana e que funcionam como identificadores regionais. São pontos de referência de amplitude variável, de acordo com a perspectiva a ser adotada e conforme a relação estabelecida entre os níveis continental/subcontinental, subcontinental/regional, regional/local. Em resumo, são produtores de escalas analíticas para as relações internacionais.

Da sua parte, a escala sul-americana passa a sustentar-se não na homogeneidade, mas na diversidade de sub-regióes existentes na América do Sul. O respeito a estas singularidades fornece a linha de ação costurada pelo exercício político-diplomático para dar origem a uma mesma tessitura integracionista. A diversidade e a riqueza desse panorama se refletem nas estratégias de inserção internacional das várias sub-regiōes latino-americana, centro-americana, caribenha, amazônica, andina e sul-americana. Nas palavras de Luis Felipe de Seixas Correa (2000): "Há uma diferenciação natural. Cada sub-região segue um caminho condizente com suas realidades políticas e econômicas, que se somam ao sentimento comum, sempre presente, de identidade histórica, cultural e humana entre o conjunto da América Latina e Caribe".

A título de ilustração, o surgimento de complexos regionais, como o andino, o platino e o amazônico, fornecem racionalidade específica para se pensar as grandes questôes internacionais, como segurança ambiental, energética e climática. Como uma escala analítica, o conceito de América do Sul é um identificador dos países a ela pertencentes em relação a outros continentes e regiōes, sendo ponto de partida 
para a consolidação de uma identidade sul-americana, mais ampla em todos os aspectos. Por fim, a identificação regional junta-se ao fator nacional como elemento de influência na determinação de políticas públicas dos países.

\section{A construção da identidade sul-americana}

Como aconselham Langehoven e Slocum (2005, 139), "to understand identity a researcher must examine the ways in which the concept is used and to what ends". Entender a noção de identidade requer, portanto, visualizar o peso do pertencimento em nível regional, ou seja, captar de que parte do mosaico sulamericano cada país faz parte. Ademais, para Kubalkova (2001, 33), a mudança do foco de análise das capacidades para identidades significa uma mudança do que os Estados podem fazer por conta de sua posição na estrutura "to what they want to do because of how they see themselves in relation to others".

Assim sendo, as identificações regionais em conjunto compõem a identidade regional, caracterizada pela multidimensionalidade e pela não atomização e redução a uma característica única e dominante, assim como ocorre na realidade européia. Dessa maneira, o ambiente político será responsável por forjar e construir as conexões mentais e materiais entre as várias componentes, amazônica, andina, platina e caribenha, do espaço sul-americano. Logo, a identidade sul-americana pode ser desconstruída em cinco elementos essenciais: a) compartilhamento de valores e ideiass; b) definição de interesses regionais; c) montagem de uma grande estratégia regional; d) atuação pelo dualismo interno-internacional; e) não exclusão e tolerância;

Em primeiro lugar, não obstante seja fator essencial estar ligado por laços geográficos, a união natural depende do compartilhamento de valores e ideiass. A organização do espaço sul-americano viria do compartilhamento de valores brasileiros com os de seus vizinhos, como forma de enfrentar crises sistêmicas, de moldar a ordem global e consolidar a identidade sul-americana, "como identidade de países que dividem uma mesma vizinhança imediata e, por isso, como é natural, têm uma agenda própria de temas, de oportunidades, de aspiraçôes e de preocupaçôes" (CARDOSO 2000). Destarte, o estreitamento de laços transfronteiriços entre o Brasil e seus vizinhos é uma evidência empírica desse primeiro elemento.

Em segundo lugar, pela regionalização das políticas externas dos países sul-americanos. A mola propulsora vem da integração física, amparada no setor infraestrutural (telecomunicações, energia, transportes), assim como ocorreu na Europa das décadas de 1950 e 1960. Sem dúvida, depois da consolidação do marco democrático, a energia seria o fator mais importante de aproximação entre os países da América do Sul. Dessa maneira, os planos levados a cabo para integração física da América do Sul por meio da Iniciativa para a integração da infra-estrutura regional Sul-americana - IIRSA e o papel das reuniōes sistemáticas de presidentes da América do Sul são capítulos de incentivo e consolidação desse processo. 
Em terceiro, pela montagem de uma grande estratégia regional. A aproximação entre Comunidade Andina e Mercosul e o projeto da Unasul no plano regional, o alinhamento nos grandes fóruns internacionais contra as barreiras protecionistas que restringem o acesso aos mercados dos países desenvolvidos, e uma oposição sistêmica às assimetrias que distorcem a economia globalizada são evidências de um processo de construção identitária em curso na América do Sul. Como argumenta Wendt $(2005,337)$, "this sense of being part of a group or 'we', is a social or collective identity that gives actors an interest in the preservation of their culture".

Em quarto lugar, uma identidade regional sul-americana leva em consideração a dinâmica dual da vida internacional e a interrelação entre os ambientes doméstico e internacional. Assim, o respeito aos preceitos democráticos e o acesso a perspectivas mais humanistas e justas de organização social proporcionam a estabilidade interna necessária à inserção internacional e facilitam modificações identitárias individuais dos agentes. Conforme exposto, a ajuda mútua e a responsabilidade sistêmica, consubstanciadas no elemento da solidariedade, podem produzir um princípio de política exterior a guiar o país em seu relacionamento com os vizinhos sulamericanos. Como atesta Cardoso (2000), "só teremos êxito se formos capazes de ser companheiros dos outros países. Não podemos sufocar, tirar vantagem desnecessária. A vantagem é estratégica, não é para o dia de amanhã”.

Por último, um caráter não-excludente é marcante da composição da identidade regional sul-americana em dois momentos: a) porque não exclui laços bilaterais ou multilaterais com os outros países da América Latina, do continente americano ou do mundo; b) porque não exclui a pluralidade intrínseca à própria América do Sul e ao Brasil, cuja identidade é plural também. Caberia à geografia o papel de "inventar" um sentimento regional baseado na idealização do território sul-americano, "ancorando-o na natureza, cartografando as suas fronteiras, descrevendo as suas paisagens" (MAGNOLI 2001, 8).

Portanto, a identidade sul-americana emerge como uma identidade coletiva proveniente do florescimento de uma cultura política sul-americana. Para Wendt, "its political culture is the most fundamental fact about the structure of an international system", pois dá significado ao poder e aos interesses dos atores. Uma mudança na estrutura envolve uma mudança na identidade coletiva dos agentes, "involving the breakdown of an old identity and the emergence of a new", o que ocorre com a inclusão do conceito de América do Sul nos discursos diplomáticos e a reconfiguração da ordem internacional após o 11 de setembro de 2001 (WENDT 2005, 250 e 238).

O despertar da consciência regional advém de um lento processo histórico, assim como a construção da imagem referenciada de sul-americanidade. Isto significa desenvolver uma consciência de alteridade da América do Sul sobre o “eu” regional e o "outro" (Países Árabes, África, Europa). Este processo está em curso e as palavras de Celso Amorim são esclarecedoras: "sou muito sul-americano e não tenho nenhuma dificuldade em dizer ao mundo que a América do Sul tem sua personalidade" (AMORIM 2007, 111). 


\section{A sul-americanidade na construção de imagens}

Uma vez inventada, a ideia de América do Sul passa a projetar imagens e deixar sombras históricas sobre a tela de acontecimentos e fenômenos da vida internacional, o que será apreciado nesta seção. A formação de imagens mentais sobre a realidade passa pela criação de novas ideias mediante a combinação de experiências anteriores. Segundo René Girault (2004,73-85), a mídia e os encontros internacionais de todo tipo fazem evoluir a imagem que as nações têm delas mesmas e das outras. Três imagens são geradas e percebidas pelas coletividades sobre a presença brasileira na América do Sul: o estereótipo hegemônico, o perfil de liderança e a alteridade hispânica.

\section{A imagem hegemônica}

A primeira imagem é relevante pois traz dificuldades para a sociabilização do país no espaço sul-americano. Apesar da ideia de um Brasil hegemônico ser tomada por alguns estudiosos como um estereótipo do conhecimento, a Cúpula dos Chefes de Estado da América do Sul, realizada em Brasília em 31 de agosto de 2000, provou o contrário, uma vez que ali se intensificaram os debates sobre o papel internacional do Brasil na região.

A apreciação do conceito de hegemonia aplicado à realidade do Brasil nos remete aos primeiros anos do século XX, e traz consigo reflexos das aventuras imperiais do Brasil na região do Prata. O Barão do Rio Branco procurou orientar a política exterior do país contra as "rivalidades estéreis dos países sul-americanos", com as quais não queria envolvimento. Ao contrário, a "cordial simpatia" era o princípio básico de relacionamento no espaço sul-americano, respaldado na grandeza do país. Em 1909, Rio Branco apontara: "o Brasil entrou resolutamente na esfera das grandes amizades internacionais, a que tem direito pela aspiração de sua cultura, pelo prestígio de sua grandeza territorial e pela força de sua população" (BUENO 2002, 165).

Pode-se recuar um pouco mais no tempo sul-americano e apreciar a gênese da visão de um Brasil imperialista como uma das forças de afastamento em relação a seus vizinhos. O Brasil interveio sistematicamente em sua vizinhança, como no Uruguai e no Paraguai; envolveu-se em conflito de grande magnitude na esfera regional, tornando a Guerra do Paraguai o mito fundador da opulência militar do país na região; teria responsabilidade direta na criação de países do Cone Sul, como a Argentina; envolveu-se em corridas armamentistas advindas de disputas navais, com Peru e Argentina; possuía prestígio internacional: bons contatos na Europa e relações privilegiadas com os EUA. Enfim, o Brasil acumularia uma série de atributos que o diferenciava dos outros países da região, projetando uma imagem de superioridade e opulência. Respaldada em sua pretensa grandeza a 
diplomacia brasileira se dava ao luxo de ser generosa e solidária com os vizinhos, como no caso da cessão da Lagoa Mirim ao Uruguai.

Se, por um lado, a atuação internacional do país alimentou essa visão negativa que viria a consolidar o estereótipo de um Brasil hegemônico, por outro a chancelaria brasileira sintonizara-se com tal imagem e passou a utilizá-la como referencial para instrumentalizar sua atuação no âmbito regional, na medida em que criou regras de convivência de dois tipos: cooperativas, como a cordialidade oficial e a diplomacia da concessão, e impeditivas, como a diplomacia da obstrução.

\section{A imagem de líder}

A segunda imagem projeta o Brasil como líder na América do Sul. De forma breve, pode-se definir a liderança pela disposição de uma potência de representar os interesses de outras nações, guiar um grupo de países de acordo com grandes objetivos de política exterior, identificar e agir sobre desafios e oportunidades na arena internacional e mediar conflitos e desentendimentos entre os agentes da sociedade internacional. Em decorrência pode-se desconstruir o conceito de liderança em três elementos: visão do outro, vontade de desempenhar o papel social de líder e os meios de liderar.

Os meios de liderança vinculam-se aos tradicionais elementos de poder (econômico, tecnológico, militar etc) sob as fórmulas do hard power, soft power e smart power. Não obstante, precisam ser relacionados com a legitimidade advinda da aquiescência, do interesse mútuo e do consentimento dos agentes. Logo, liderança não se exerce exclusivamente por meio de ameaças e incentivos, mas por meio de um processo de "sociabilização" e transformação das ideias dos agentes de determinado arranjo social. Aqui, vale ressaltar a diferença entre hegemonia e liderança, que depende da visão do outro.

A vontade de liderança acopla-se ao prestígio internacional e à regulação da ordem internacional. Assim, ter sua força reconhecida pelas outras naçóes possibilita que se atinjam objetivos sem ter de usá-la (WIGHT 2002, 87-90). Além disso, a sagacidade em produzir e modificar normas no plano internacional, que pode ser denominado de poder normativo, é um incentivo à liderança. Lembra Onuf (1998: 60), "rules make it possible for us to act on behalf of social constructions", estabelecendo uma condição em que agentes usam-nas para exercitar controle e obter vantagens sobre outros agentes. Logo, enquanto Estados comuns seguem as regras, Estados poderosos criam as regras e interferem diretamente no processo de construção dos arranjos sociais.

Com relação ao Brasil, lembra Bueno (2002 181) que não se incluía entre os objetivos brasileiros no começo do século XX, a pretensão à hegemonia, mas sim uma influência compartilhada com a Argentina nas questóes sul-americanas. Esta influência compartilhada evoluiu do arranjo triangular imaginado pelo Barão e exaltado por Perón, entre Argentina, Brasil e Chile (ABC), até encontrar-se 
com a figura do Mercosul na década de 1990, ao incorporar Paraguai e Uruguai (CISNEROS e IÑIGUEZ 2002). Além disso, o Mercosul ampliado (Chile, Bolívia, Peru e Venezuela) e o avanço institucional regional pela UNASUL têm eclipsado a visão hegemônica, evidenciando a imagem de uma liderança regional brasileira na América do Sul.

Dentro da própria chancelaria brasileira, admite-se a diferenciação que existe entre o Brasil e seus vizinhos, o que se traduziria em meios de liderança regional: "O Brasil tem de desempenhar um papel compatível com o seu tamanho [...] é claro que não é um país igualzinho aos outros do ponto de vista econômico, de território, tem recursos naturais, mercado, portanto, tem seu peso específico" (LAMPREIA 2000a). Em síntese, vale a assertiva de Azeredo da Silveira, ecoada em discurso por Celso Amorim (2007, 306): "você pode renunciar a muitas coisas, mas não à grandeza”.

\section{Imagem de não hispânico}

A imagem de não hispânico apóia-se na noção de hispanidad e projeta um Brasil diferente, em determinados momentos, irreconciliável com o padrão sóciocultural sul-americano. A alteridade se sustenta sobre bases de percepções históricas, lingüísticas e políticas de demonstração de diferenciação quanto às identidades. Nas palavras de Miguel Unamuno: "quiero decir com hispanidad una categoria histórica, por lo tanto espiritual, que há hecho, en unidad, el alma de um território com sus contrastes y contradicciones interiores" (Apud. DUHALDE 2006, 235).

No primeiro plano, a base histórica da alteridade reside no âmago do processo de independentização latino-americano. O pensamento de Simon Bolivar era claro: "Por desgracia el Brasil linda con todos nuestros Estados: por consiguiente tiene facilidades para hacernos la guerra con suceso, como lo quiere la Santa Alianza" (PORTILLO 1983, 23). Após impulsionar o processo de independência da GrãColômbia (Colômbia, Venezuela, Equador e Panamá), do Peru e Bolívia, Bolívar posicionava-se preventivamente com relação ao Brasil. Logo, a identidade comum das repúblicas hispano-americanas delimitava um universo de diferenciação em três elementos: Península Ibérica, América do Norte e o vizinho lusófono-imperial. Era um universo diferenciador calcado na percepção de ameaças: uma possível ação coordenada de Portugal e Espanha para recolonização, o novo horizonte expansionista e agressivo dos Estados Unidos da América e as incertezas acerca do Império luso-brasileiro.

No segundo plano, ao resgatar as preocupaçóes evidenciadas por Bolívar, Rio Branco sabia que o Brasil encontrava resistências no espaço sul-americano e para tanto procurou mitigar tais visões: "por não sermos país de língua espanhola houve sempre na América espanhola grandes preconceitos e desconfianças e que pela nossa parte procuramos ir modificando pela cordura e pela longanimidade com que suportamos alguns de nossos vizinhos" (BUENO 2002, 168). Porém, 
Rio Branco não tendia para o lado do afastamento, pelo contrário, se esforçou em dirimir as diferenças de cultura e língua e as visões de imperialismo hegemônico que pudessem impedir a união da região (RICUPERO 1995).

No terceiro plano, a modernização das preocupações externas com relação a possíveis tendências hegemônicas brasileiras diante dos vizinhos sul-americanos marca o continuum do caráter diferenciador da língua e cultura hispânica, em relação à herança lusófona do Brasil e trazem consigo indagações e desconfianças sobre as perspectivas da participação brasileira em arranjos sociais integrativos na América do Sul. Este debate pode ser apreciado pelo grande número de artigos de revistas e jornais veiculados pela imprensa brasileira e internacional na época da I Reunião de Presidentes da América do Sul (Brasília-2000). ${ }^{1}$

Por fim, enquanto os brasileiros utilizam a noção de sul-americanidade como elemento identitário, argentinos e demais sul-americanos se apegam à noção de "irmandade", que traduziria mais fielmente os propósitos regionalistas hispano-americanos. Segundo Eduardo Duhalde, "este concepto de hermandad es uma característica básica de la unión sudamericana, que nos diferencia del resto de los procesos de integración que se observan en el mundo" Aflora, dessa maneira, um conflito entre as ideias de América do Sul emanadas das chancelarias sulamericanas, o que pode gerar distorções no redesenho do mapa sul-americano. Duhalde alerta ainda que "Nosotros, aún lejos de ser uma Nación, nos consideramos hermanos y no descubrimos todavía las conveniencias de la conviência en familia". (DUHALDE 2006, 32-33).

\section{A institucionalização da ideia de América do Sul}

Conscientes das imagens projetadas acerca do Brasil no mundo, estadistas incorporaram de forma ciclotímica, em seus cálculos estratégicos, o espaço sulamericano como prioritário. A consistência emerge com a reinvenção do conceito no ano 2000, na I Reunião de Presidentes da América do Sul. Neste momento, a ideia de América do Sul é forjada nos discursos diplomáticos e o conceito passa a representar a realidade de conformação de um "sistema sul-americano de cooperação econômica e política” (JAGUARIBE, 2000).

A institucionalização da ideia de América do Sul passa por um processo histórico de incremento dos diálogos diplomáticos e construção de um edifício integrativo, como um esforço genuíno de transformar identidades egoístas em uma identidade coletiva. A ideia de América do Sul foi acoplada aos projetos e à

\footnotetext{
1 Ver, a título de exemplo: BRASIL assume a liderança regional. Jornal O Globo, 31 de agosto de 2000. BRASIL ensaiou liderança regional em cúpula de líderes sul-americanos. Jornal O Globo, 03 de setembro de 2000. JORNAIS citam liderança do Brasil. Folha de São Paulo, 01 de setembro de 2000. LIDERANÇA compartilhada. Correio Braziliense, 2 de setembro de 2000. p.8. LOHBAUER, Christian. O papel do Brasil como líder sul-americano. Valor Econômico, 16 de março de 2001. ONUKI, Janina. Liderança sem rumo. Folha de São Paulo, 19 de setembro de 2000.
} 
estratégia internacional do Brasil ao final do século XIX e evoluiu até meados do século XX como guia na construção do eixo bilateral com a Argentina. O ensaio da integração foi engatilhado entre 1955 e1963, mas não se alinhou ao descompasso venezuelano nem à postura de força dos presidentes-generais, sendo obscurecido de vez pela ascensão dos regimes militares. Assim, em um momento de desconfiança mútua não havia possibilidade de entendimentos em nível tal como o pretendido com a Reunião de Brasília.

A construção da confiança sul-americana partiu da entente Brasil-Argentina que foi revitalizada com os governos Geisel e Figueiredo e avançaria sob eixos claros de entendimento como a aliança energética, o processo de integração econômica e a colocação da democracia como objetivo maior para todos os países. Do outro lado, a grande estratégia norte-americana de dominação econômica continental, com a "Iniciativa para as Américas" e o Nafta, acabou por fortalecer o regionalismo sul-americano. De qualquer forma, segundo Lampreia (2000b), "a continuidade e aprofundamentos democráticos, que englobam o Mercosul e toda a América do Sul, fazem possível convocar hoje uma reunião de presidentes como a de Brasília no ano de 2000". Além disso, as reuniōes de presidentes de Brasília (2000) e Guaiaquil (2002) serviram como plataforma de lançamento de objetivos comuns em política externa no plano infraestrutural, sem precedentes na história da região, que aproveitou uma base cultural comum para redimensionar o quadro identitário do sistema sul-americano de países.

Coube ao governo Lula assumir a sul-americanidade como herança histórica e, gradativamente, institucionalizar a ideia de América do Sul por meio de discursos e ações. Em $1^{\circ}$ de janeiro de 2003, Celso Amorim assumia a pasta dos assuntos exteriores exaltando "uma América do Sul politicamente estável, socialmente justa e economicamente próspera [como] um objetivo a ser perseguido não só por natural solidariedade, mas em função de nosso próprio progresso e bem-estar" (AMORIM 2007, 15). A institucionalização seguiria no caminho da criação da Subsecretaria-Geral para a América do Sul que "nos fornecerá uma estrutura melhor aparelhada para esta imensa articulação diplomática com nossos vizinhos sul-americanos" (AMORIM 2007, 127-129).

As adequações na rotina decisória do Itamaraty se deram juntamente com as discussões acerca da agenda comercial hemisférica. O Brasil aproveitava para posicionar a América do Sul como nexo entre os interesses brasileiros e de seus vizinhos, denunciando as incompatibilidades inerentes à ALCA. Amorim ressaltara que "o diálogo entre nós é fundamental não só para as negociações da ALCA, mas para a própria integração sul-americana, nossa principal prioridade" (AMORIM 2007, 192).

Celso Amorim reiteraria o fato de ser a América do Sul o local "onde o Brasil pode ter um impacto positivo e compor-se com países cuja evolução também tenham um impacto imediato no Brasil” (AMORIM 2007, 279-280). Nesse sentido, os desafios da agenda de segurança pós-11 de Setembro incluíam 
a instrumentalização do conceito de América do Sul. Ao falar sobre os novos conceitos globais e hemisféricos de segurança, esclareceu que o objetivo principal da política externa brasileira é o de consolidar o estatuto da América do Sul como um espaço de paz, diálogo e cooperação, possibilitando concentrar esforços no desenvolvimento econômico e social. Para Amorim a "América do Sul mais unida e coesa poderá afinar posições e melhor refutar conceitos e iniciativas questionáveis" (AMORIM 2007, 207-208).

Com a continuidade das reuniōes de presidentes e chefes de estado da América do Sul (Cuzco - 2004 e La Paz - 2006) e com a sistematização dos encontros entre os chanceleres dos países sul-americanos, rumou-se para a conformação da Comunidade Sul-Americana de Naçôes (Casa) em 2007 e para o estabelecimento da União Sul-Americana (2008). Conseqüentemente, constrói-se o ambiente político e institucional necessários à internalização da ideia de América do Sul como conceito operacionalizável das políticas exteriores de seus países.

Como coloca Lafer (2002), ao citar Ortega e Gasset, "para cada geração, viver é uma tarefa com duas dimensóes: a primeira diz respeito a receber o vivido pela antecessora, tanto ideias, valores como instituiçóes; a outra, seria a de reagir a seu modo diante do novo". Neste sentido, a definição do projeto América do Sul dentro da chancelaria brasileira funcionaria, ao mesmo tempo, como resgate das tradiçôes perpetuadas na evolução do relacionamento do Brasil com o restante do continente, bem como reação às novas imposiçôes da ordem internacional do século XXI, na perspectiva de tornar a América do Sul uma referência para as gerações política e diplomática vindouras.

\section{Considerações finais}

Um desígnio histórico da chancelaria brasileira é o de retificar as falhas no caminho da integração regional. Para tanto, fazia-se necessário construir um conceito que representasse uma nova referência identitária para suas sociedades, populações e grupos políticos internos. A construção da América do Sul passou por um processo de reinvenção conceitual em três tempos e que teve sua maturação entre 2000 e 2008. Primeiro, foi apropriado pela intelectualidade e pelo pensamento diplomático que se esforçavam em definir os espaços privilegiados de atuação do Brasil no mundo. Segundo, foi inserido no discurso pela utilização sistemática e tomando-se como referencial a identidade regional sul-americana. Terceiro, alcançou a institucionalização com o soerguimento das instituições político-diplomáticas regionais no início do novo milênio.

Não obstante, percebe-se que o conceito de América do Sul produz sombras sobre as imagens da realidade regional. Conforme alerta Duroselle (2002, 33), "o problema dos conceitos é que eles adquirem vida subrepticiamente, uma vida totalmente artificial". Como conseqüência, a sul-americanização da política exterior produziu dois efeitos de distorção: a) induziu à construção de uma imagem não 
representativa da multiplicidade identitária que compõe o arranjo social regional; e b) reduziu as camadas de percepção acerca da identidade internacional do Brasil. Em síntese, eclipsou o universalismo da política externa brasileira, nublando os vários céus que compõem o horizonte das relações internacionais do Brasil.

A construção pela invenção da América do Sul ancorou os governos FHC e Lula à força da tradição, constituindo-se em norte da inserção internacional brasileira na última década. Paradoxalmente, a percepção crítica do ocaso da ideia de América do Sul como ponto focal para as tomadas de decisão na política externa brasileira deve conduzir a uma correção de rumos e a uma nova calibragem dos direcionamentos e alcances internacionais do Brasil.

Por fim, o Brasil continua sendo americano, latino-americano, iberoamericano e sul-americano e a restrição conceitual não se interpõe às várias camadas identitárias do país. Ademais, a diplomacia brasileira evolui segundo a contraposição de dois vetores: um utópico, voltado para a transformação das relaçōes sociais, e outro mítico, regressivo, voltado para a perpetuação do status quo e valorização do tradicional. Assim, partindo-se do Barão do Rio Branco - a política externa é o reino da tradição, não da invenção - seria também razoável afirmar que a política externa é o reino da tradiçāo inventada.

Recebido em 17 de dezembro de 2008

Aprovado em 20 de julho de 2009

\section{Referências bibliográficas}

ADLER, Emmanuel. 2002. "Constructivism and international relations". CARLSNAES, Walter; RISSE, Thomas; SIMMONS, Beth A. Handbook of International Relations. Sage Publications.

ALBUQUERQUE, J. A. Guilhon. 1997. “As Américas do Sul”. SEMINÁRIO América do Sul: 2006. Disponível em http://www2.mre.gov.br/ipri/SAMERICASUL.html. Acessado em 15 de dezembro de 2008.

ALEIXO, José Carlos Brandi. 2000. O Brasil e o Congresso Anfictiônico do Panamá. RBPI, 43, 2: 170-191.

AMORIM, Celso. Coletânea do Ministério das Relaçôes Exteriores: Política Externa Brasileira vol. II: discursos, artigos e entrevistas do Ministro Celso Amorim (2003-2006). Brasília, Secretaria de Planejamento Diplomático, 2007.

BANDEIRA, Luiz Alberto Moniz. 2003. Brasil, Argentina e Estados Unidos - conflito e integração na América do Sul (Da tríplice Aliança ao Mercosul: 1870 a 2003). Rio de Janeiro: Revan.

BUENO, Clodoaldo. 2003. Política Externa da Primeira República: os anos de apogeu (de 1912 a 1918). São Paulo: Paz e Terra.

BUENO, Clodoaldo . "O Barão do Rio Branco e o Projeto da América do Sul”. In FUNAG. 2002. Rio Branco, América do Sul e a Modernização do Brasil. Brasília: IPRI/FUNAG. 
CARDOSO, Fernando Henrique. 2000. DISCURSO do Presidente da República na Solenidade de Formatura dos Alunos do Instituto Rio Branco - Palácio Itamaraty 18 de maio de 2000. Disponível em http://ftp.unb.br/pub/UNB/ipr/rel/discpr/2000/2916.pdff. Acessado em 10 de dezembro de 2008.

CERVO, Amado Luiz. 2008. Inserção internacional: formação dos conceitos brasileiros. São Paulo: Saraiva.

CISNEROS, Andrés e IÑIGUEZ, Carlos Piñeiro. 2002. Del ABC al Mercosur: la integracion latinoamericana em la doctrina y práxis del peronismo. Buenos Aires: ISEN/Nuevo Hacer/ Grupo Editor Latinoamericano.

CORREA, L. F. Seixas. 2000. Uma agenda da América do Sul. Revista Archivos del Presente: Buenos Aires, ano 5, n 20: abr-jun 2000.

COUTO, Leandro. 2007. O horizonte regional do Brasil e a construção da América do Sul. RBPI, ano 50, vol 1, 163.

DANESE, Sérgio. 1999. Diplomacia presidencial. Rio de Janeiro: Top Books.

DUHALDE, Eduardo. 2006. Comunidad Sudamericana: logros y desafios de la integración. Buenos Aires: Planeta.

DUROSELLE, Jean-Baptiste. 2002. Todo imperío perecerá. Brasília: Ed. UnB/São Paulo: Imprensa Oficial.

FURTADO, Celso. 1970. Formação Econômica da América Latina. 2a ed. Rio de Janeiro: Lia.

FURTADO, Celso. 2002. Em busca de um novo modelo: reflexóes sobre a crise contemporânea. São Paulo: Paz e Terra.

GIRAULT, René. 2004. Diplomatie européene: nations et impérialismes (1871-1914). Paris: Petit Bibliotheque Payot.

HEREDIA, Edmundo1998. “O Cone Sul e a América Latina”. In CERVO e RAPOPORT. História do Cone Sul. RJ. Revan.

HOBSBAWN, Eric e RANGER, Terence. 2002. A invenção das tradições. São Paulo: Paz e Terra, 2002.

JAGUARIBE, Hélio. 2000. Surge o sistema sul-americano. Jornal do Brasil, 10 de setembro de 2000.

KUBALKOVA, Vendulka. 2001. "Foreign policy, international politics and constructivism". In Foreign policy in a constructed world, KUBALKOVA, Vendulka, 33. New York: M . E. Sharpe.

LAFER, Celso. 2002. Um diálogo de gerações. Jornal O Globo, 26 de agosto de 2002.

LAMPREIA, Luiz Felipe. 2000a. Brasil lidera continente sem imposição. Correio Braziliense, 24 de agosto de 2000.

LAMPREIA, Luiz Felipe. 2000b. Peru pode ser criticado, diz ministro. Entrevista. Folha de São Paulo, 28 de agosto de 2000.

MAGNOLI, Demetrio. 2001. O corpo da Pátria. São Paulo: Edusp.

ONUF, Nicholas. 1998. "Constructivism: a user's manual". In International relations in a constructed world, KUBÁLKOVÁ, Vendulka; ONUF, Nicholas; KOWERT, Paul (ed.). 59-64. Armonk, NY: M.E. Sharpe. 
PORTILLO, Julio. 1983. Venezuela-Brasil: Relaciones diplomáticas 1842-1982. Caracas: Editorial Arte.

RAPOPORT, Mario. 2002. Tiempos de crisis, vientos de cambio: Argentina y el poder global. Buenos Aires: Grupo Editorial Norma.

RICUPERO, Rubens. 1995. O Barão do Rio Branco: uma biografia fotográfica. Brasília: FUNAG.

SINGER, Paul. 1997. “América do Sul 2006: da Geografia à História”. Seminário América do Sul 2006. Disponível em http://www2.mre.gov.br/ipri/SAMERICASUL.html. Acessado em 15 de dezembro de 2008 .

SLOCUM, Nikki e VAN LANGEHOVEN, Luk. 2005.“Identity and regional integration”. In Global politics of regionalism: theory and practice, FARELL, Mary et alli. 138 e 142. London: Pluto Press.

WENDT, Alexander. 2005. Social Theory of international politics. Cambridge: Cambridge University Press.

WIGHT, Martin. 2002. A política do poder. Brasília: UnB.

\section{Resumo}

Este artigo pretende mostrar que a construção da América do Sul derivou da reinvenção de um conceito, utilizado no discurso e na prática diplomática brasileira, e amparado em elementos de alteridade como latino-americanidade, hegemonia, liderança e hispanidade. O texto rastreia a ideia de América do Sul desde suas origens intelectuais até a institucionalização em arranjos político-diplomáticos regionais.

\section{Abstract}

This article intends to show that the South America construction came from a concept reinvention. It is used in the speech and practice of Brazilian diplomacy and is based on elements related to hegemony, lidership, hispanic and latin-american identiy. The text tracks the idea of South America since its intelectual origins until its institucionalization in regional political and diplomatic arrangements.

Palavras-chave: América do Sul; História das Relações Internacionais do Brasil; Rastreamento de ideias.

Keywords: South America; History of Brazilian International Relations; Tracking ideas. 